\title{
Study on Developmental- Behavioural Pediatrics Training Experiences of Pediatricians and Pediatric Trainees Working in Nepal
}

\author{
Rimal HS, ${ }^{1}$ Pokharel A, ${ }^{2}$ Saha $V^{1}$
}

\author{
${ }^{1}$ Department of Pediatric \\ ${ }^{2}$ Department of Psychology \\ Nobel Medical College Teaching Hospital \\ Biratnagar, Nepal
}

\section{Corresponding Author}

Hem S Rimal

Department of Pediatric

Nobel Medical College Teaching Hospital

Biratnagar, Nepal

E-mail: hemsagarr@yahoo.com

Citation

Rimal HS, Pokharel A, Saha V. Study on Developmental- Behavioural Pediatrics Training Experiences of Pediatricians and Pediatric Trainees Working in Nepal. Kathmandu Univ Med J 2013;43(3):191-195.

\section{ABSTRACT}

\section{Background}

There are growing concerns about developmental, behavioural, social and emotional wellbeing of children throughout the world. A huge gap exists between the instructions provided on medical disciplines and on areas of Developmental- Behavioural Pediatrics (DBP) during pediatric training in our region.

\section{Objective}

This study aims to evaluate the Developmental -Behavioural pediatrics (DBP) training experiences of pediatricians and pediatric trainees during their post graduate training in pediatrics.

\section{Methods}

Questionnaires were sent to the pediatricians / trainees and data was analyzed using SPSS software.

\section{Result}

More than $56 \%$ of respondents were satisfied in 10 out of 11 medical disciplines where as more than $56 \%$ were unsatisfied in 10 out of 11 developmental behavioural pediatrics disciplines. This Study has demonstrated that between $50-60 \%$ of pediatricians did not see the cases of ADHD, Learning difficulty and family dysfunction for a period of three months prior to the survey which are relatively common conditions. Even in post graduate training nearly $66 \%$ of pediatricians were unsatisfied with their instructions in DB pediatrics.

\section{Conclusion}

Pediatricians working in Nepal have difficulties in addressing the issues of developmental pediatrics, raising a question about the need to review the curriculum of post graduate training in Pediatrics.

\section{KEY WORDS}

Developmental pediatrics, evaluation, multidisciplinary team, training

\section{INTRODUCTION}

Throughout the world, there are growing concerns about Developmental, Behavioural, Social and Emotional wellbeing of Children. ${ }^{1}$ Childhood psychosocial dysfunction was described as part of the "new morbidity". more than 35 years ago. ${ }^{2}$ As the threat of acute infectious diseases are decreasing the issues of Developmental-Behavioural Pediatrics, are now considered as important areas to focus on. The time has come now, for all the pediatricians to realize their role to look after children with DevelopmentalBehavioural Pediatric (DBP) issues.
There is a huge gap between the instructions provided on medical disciplines and on areas of DBP during pediatric training in our region. Hence, there is a strong demand for trained developmental pediatricians and child psychiatrists in our region to meet the demands of the changing needs of society.

This study aims to explore how satisfied pediatricians/ Pediatric trainees (working in Nepal) were with the instructions given in medical disciplines as compared to developmental behavioural disciplines, during their Post 
graduate training in Pediatrics. This study also reports on the existing concept and practice of working within a multidisciplinary team and referral to allied health professionals. There has been no such study in Nepal in the DB pediatrics subspecialty area and it has raised question about the necessity of reviewing of the curriculum of post graduate training in Pediatrics.

\section{METHODS}

A Survey questionnaire was sent to most of the pediatricians and pediatrics trainees at various medical colleges in Nepal. The questionnaires were received by post or electronically. The questionnaire contained 4 sections:

1. Demographic information that included year of graduation, year of training for a trainee and also the year of completion for the Pediatrician. They were also asked how satisfied they were during their pediatric training on 11 DBP issues that included behavioral issues, child abuse, unsettled baby, intellectual disability, learning difficulty,emotional problem, ADHD,Adolescent problems, pediatric rehabiliatation, developmental delay, and disabilities(cerebral palsy, severe neurological problem). The behavioral issues include anger related problems and oppositional problems. Unsettled baby are babies who are difficult to settle and they are irritable and crying all the time. Intellectual disability is a disability due to intellectual sub-normality and is evaluated by a psychologist through the measurement of intelligent quotient (IQ). The learning difficulties are problems of school children who have difficulty learning maths, science or reading books. Disabilities include cases of cerebral palsies, children with severe physical and neurological problems. ADHD is an attention deficit hyperactivity disorder in which children have poor attention span, impulsivity and hyperactivity that affect childrens academic performance. The adolescent issues are specific to adolescent age group that includes peer problems, substance abuse, smoking etc. Pediatric rehabilitation is an area where children with disabilities and several other behavioral issues are dealt with to improve their quality of life. The developmental delay is abnormal developmental trajectory noted in children across one or more of the developmental domains i.e gross motor, fine motor, social and interpersonal, hearing, vision, speech and language. Pediatricians and trainees were asked about their recent experiences of seeing cases in the DBP discipline.

2. Respondents were also asked whether they had been jointly managing cases in multidisciplinary manner.

3. They were asked whether the instruction on DB pediatrics during undergraduate and postgraduate training was satisfactory or not along with overall rating of post graduate training in Pediatrics.

4. They were also asked whether their training in 11 Medical discipline(General Pediatrics, Neonatology, Pediatric
ICU, Cardiology, Nephrology, Neurology, Respiratory, Gastroenterology, Hematology, Endocrinology, Immunolgy) was satisfactory or not.

The ratings of satisfaction with instructions in the Developmental-Behavioural Pediatrics (DBP) and medical disciplines were recorded as 1 (unsatisfactory), 2(satisfactory) and 3(very satisfactory)based on the ratings of Pediatricians and trainee..Data was analyzed using SPSS software version 16 . The average score was calculated for each candidate in Medical and DB discipline separately as the mean of ratings for 11 DBP and 11 medical disciplines. These scores were then compared using paired $t$ test.

\section{RESULTS}

Fifty three of the 85 surveys were returned completed, by post or email giving a survey response rate of 62.66 $\%$. Among the respondents, 47 were pediatricians and 6 pediatric trainees of which 49 had Nepal as country of residence and 4 had others. Nearly sixty six percentage of respondents have had working experience of $>5$ years and $34 \%$ had experience of $<5$ years. The median years of work experience of doctors (IQR) was 6(3.5-9.00).

The rate of satisfaction with teaching and training on Medical and Developmental and Behavioural pediatrics (DBP) are shown in table 1 and 2. In 10 out of 11 medical disciplines, more than $56 \%$ respondents were satisfied where as in DBP disciplines more than $56 \%$ respondents were unsatisfied in 10 out of 11 DBP disciplines. Thus the training in Medical disciplines was much more satisfying than the training in DB pediatrics discipline which was statistically significant with $p$ value $<0.05$ (table 3 ).

There is a significant proportions of Pediatricians and trainee who didn't see any cases of children with $\operatorname{ADHD}(51 \%)$, Learning difficulty (66\%),Behavioural issues(51\%), Family dysfunction(52.8\%)and emotional disorder(34\%) over a period of three months(table 4).

Table 1. Ratings of training experience of respondents in medical disciplines.

\begin{tabular}{|lcc|}
\hline Medical discipline & Satisfactory $\mathbf{N}(\%)$ & $\begin{array}{c}\text { Unsatisfactory } \\
\mathbf{N}(\%)\end{array}$ \\
\hline General pediatrics & $53(100)$ & $0(0)$ \\
\hline Neonatology & $52(98.1)$ & $1(1.9)$ \\
\hline Respiratory & $51(96.2)$ & $2(3.8)$ \\
\hline Neurology & $35(66)$ & $18(34)$ \\
\hline Paediatric ICU & $45(84.9)$ & $8(15.1)$ \\
\hline Cardiology & $34(64.2)$ & $19(35.8)$ \\
\hline Haemato/oncology & $30(56.6)$ & $23(43.4)$ \\
\hline Endocrinology & $23(43.4)$ & $30(56.6)$ \\
\hline Immunology & $30(56.6)$ & $23(43.4)$ \\
\hline Nephrology & $35(66)$ & $18(34)$ \\
\hline Gastroenterology & $49(93.5)$ & $4(9.5)$ \\
\hline
\end{tabular}


Table 4. Number of patients seen over the $\mathbf{3}$ months period with following diagnosis.

\begin{tabular}{|c|c|c|c|c|c|c|c|c|c|c|}
\hline \multirow[t]{3}{*}{ Diagnosis } & \multicolumn{10}{|c|}{ Diagnosis Number of patients seen } \\
\hline & \multicolumn{2}{|c|}{0} & \multicolumn{2}{|c|}{$1-2$} & \multicolumn{2}{|c|}{ 3-5 } & \multicolumn{2}{|c|}{$\geq 6$} & \multicolumn{2}{|c|}{ Total seen } \\
\hline & $\mathbf{N}$ & $\%$ & $\mathbf{N}$ & $\%$ & $\mathbf{N}$ & $\%$ & $\mathbf{N}$ & $\%$ & $\mathbf{N}$ & $\%$ \\
\hline ADHD & 27 & 50.9 & 22 & 42.5 & 1 & 1.9 & 3 & 5.7 & 26 & 49.1 \\
\hline Learning difficulty & 37 & 66.0 & 12 & 21.6 & 6 & 11.3 & 0 & 0 & 18 & 34.0 \\
\hline Behavioral issues & 27 & 50.9 & 18 & 34.0 & 4 & 7.6 & 4 & 7.5 & 26 & 49.1 \\
\hline Family dysfunction & 28 & 52.8 & 19 & 35.8 & 12 & 11.4 & 0 & 0 & 25 & 47.2 \\
\hline Emotional disorder & 18 & 34.0 & 28 & 52.8 & 3 & 5.7 & 4 & 7.5 & 35 & 66.0 \\
\hline
\end{tabular}

Table 2. Ratings of training experience of respondents on DB disciplines:

\begin{tabular}{|lll|}
\hline $\begin{array}{l}\text { Developmental paediat- } \\
\text { rics disciplines }\end{array}$ & \multicolumn{1}{c|}{$\begin{array}{c}\text { Satisfactory } \\
\mathbf{N}(\%)\end{array}$} & $\begin{array}{c}\text { Unsatisfactory } \\
\mathbf{N}(\%)\end{array}$ \\
\hline $\begin{array}{l}\text { Behavioural issues in } \\
\text { children }\end{array}$ & $22(41.5)$ & $31(58.5)$ \\
\hline Unsettled baby & $21(39.6)$ & $32(60.4)$ \\
\hline Child abuse/ neglect & $15(28.3)$ & $38(71.7)$ \\
\hline Disabilities & $23(43.4)$ & $30(56.6)$ \\
\hline Intellectual disability & $19(35.8)$ & $34(64.2)$ \\
\hline Learning difficulty & $14(26.4)$ & $39(73.6)$ \\
\hline Emotional problems & $17(32.1)$ & $39(73.6)$ \\
\hline ADHD & $21(39.6)$ & $32(60.4)$ \\
\hline Adolscent issues & $25(47.5)$ & $28(52.8)$ \\
\hline Pediatric rehabilitation & $14(26.4)$ & $39(73.6)$ \\
\hline Developmental delay & $36(67.9)$ & $17(32.1)$ \\
\hline
\end{tabular}

Table 3. Comparison of rating of satisfaction in Medical and Developmental-Behavioural pediatrics (DBP).

\begin{tabular}{cllll}
$\begin{array}{c}\text { Character- } \\
\text { istics }\end{array}$ & \multicolumn{2}{c}{ Satisfaction rating } & P value & Remark \\
$\begin{array}{c}\text { Medical disci- } \\
\text { pline }\end{array}$ & Satisfied & Unsatisfied & & \\
& $22.78 \pm 5.01$ & $19.86 \pm 2.35$ & 0.029 & sig \\
\hline $\begin{array}{c}\text { Dev-Behavior- } \\
\text { aldiscipline }\end{array}$ & $21.33 \pm 5.73$ & $14.83 \pm 1.87$ & $<0.001$ & sig \\
\hline
\end{tabular}

Table 5. Ratings of training experience during undergraduate and post graduate training.

\begin{tabular}{|cll|}
\hline Training level & \multicolumn{1}{|c|}{ Satisfactory N(\%) } & Unsatisfactory N(\%) \\
\hline MBBS & $\mathbf{9 ( 1 7 )}$ & $\mathbf{4 4 ( 8 3 )}$ \\
\hline $\begin{array}{c}\text { Post graduate train- } \\
\text { ing }\end{array}$ & $18(34)$ & $35(66)$ \\
\hline
\end{tabular}

The backbone of developmental-behavioural pediatrics (DBP) practice is Multidisciplinary team approach that blends practice of pediatrics, mental health, and allied health to optimize diagnosis and management of the DBP issues. ${ }^{3}$ We found that $49 \mathrm{~b}$ to $77 \%$ of respondent had no experience of managing DB cases with any of the multidisciplinary team member.

Eighty three percent of the respondents were found to be unsatisfied about the training and instructions on DB pediatrics during their graduate training. During post graduate training $66 \%$ of respondents felt that their training in DB pediatric disorders was unsatisfactory (table 5).

\section{DISCUSSION}

This survey is the first one in Nepal aiming to find out the very crude data about the experience of Pediatricians and pediatric trainees on developmental - behavioural pediatrics during their post graduate training. This study had survey response rate of only $62.66 \%$ that will raise a question about external validity of the findings of this study. Participants were quite experienced, as $66 \%$ of respondents had working experience of more than five years.

As the burden of life-threatening acute infectious diseases is decreasing in the United States, the recognition of children with chronic medical problems and developmental and behavioural (D/B) problems is increasing. Though there is not much data from developing country but WHO and UNICEF has already started focusing on developmental disorders and early child development.

It is extremely crucial to identify and manage issues of child development and behaviour in the setting of primary care pediatrics but lots of pediatricians haven't had adequate training in developmental and behavioural pediatrics (DBP). ${ }^{4}$ This study indicated that more than $56 \%$ of Pediatricians working in Nepal were satisfied in 10 out of 11 medical disciplines where as more than $56 \%$ were unsatisfied in 10 out of 12 developmental behavioural pediatrics disciplines which is a finding similar to the study of Schor,E.L et al. ${ }^{4}$

This study has also demonstrated that very high proportions (83\%) of pediatrician felt having inadequate training and exposure in the area of developmental pediatrics during their MBBS training. Even in post graduate training nearly $66 \%$ of pediatricians were unsatisfied with their instructions in DB pediatrics. Similar finding was noted in a survey done by Grant et al where $74 \%$ of pediatric graduates felt that more of the neurology portion of residency training should have been spent on general pediatric behavioural and neurological conditions rather than very specialized pediatric neurology. ${ }^{5}$

This survey shows that there is a huge discrepancy between training in Developmental pediatrics and medical discipline 
in post graduate training in Pediatrics. Similar finding was noted in astudy done by Chee et al in developed country like Australia. ${ }^{6}$ Another study done in OHIO, USA after the introduction of the concept of one month rotation of Pediatric residents in Developmental behavioral pediatrics during their pediatric training, the comfort scores of Pediatricians were still found low in learning disabilities, behavioral problems etc. $^{7}$

The data from the 2003 National Survey of Children's Health in US reported that the most commonly diagnosed problems among children 6-17 years of age were learning disabilities (11.5\%), attention-deficit/hyperactivity disorder $(8.8 \%)$, and behavioural problems $(6.3 \%)$ and among preschoolers, speech problems (5.8\%) and developmental delay (3.2\%). ${ }^{1}$ Similarly another multicenter study done in five developing country including India found the prevalence of self-reported mental health problem as high as $10.5 \%$ with conduct and emotional problems being most common. ${ }^{8}$ Our study has demonstrated that between 50-60 $\%$ of pediatricians did not see the cases of ADHD, Learning difficulty and family dysfunction for a period of three months prior to the survey which are relatively common conditions. In a study done in Sarlahi, thirty percent of term children (29.8\%) were at risk of having disability. ${ }^{9}$ Similarly the prevalence of ADHD was found to be $12.5 \%$ among preschool children in a study done in Mumbai, India. ${ }^{10}$ Although, we don't have Nepali data on prevalence of all of those developmental - Behavioral pediatric issues but based on the available data from developing and developed country, we presume that their prevalence is high in Nepal too. As developmental problems, cognitive and emotional problem affect the school performance of children, Pediatricians must be aware of these issues to assist them to be part of their children's education. ${ }^{11}$

In response to the questions asked to obtain data and insights on their current practice, this study found that nearly $49-77 \%$ of respondents (pediatricians and trainees) managed their cases without involving any allied health professionals. In a survey of Australian Pediatrician done by Holt et al, sixty five percent of Developmental Behavioral Pediatric cases were found to be managed jointly with allied health professionals. ${ }^{12}$ The majority of neurodevelopmental disorders encountered in pediatric practice have a high incidence of co morbid conditions and rarely seem to present in isolation. Hence, the management of these issues is heavily dependent on the input from the allied health professionals but this standard practice appears lacking in our current practice

This survey has raised several questions about the extent of coverage of Developmental and behavioural pediatrics issues by the curriculum in the undergraduate and post graduate training in Pediatrics. During Postgraduate training in pediatrics, Pediatric residents need adequate training to make them competent to investigate and manage the neurobehavioral complaints and conditions commonly encountered by general pediatricians in their practice. There is a strong demand for trained developmental pediatricians and child psychiatrists in our region. ${ }^{13}$ Even in USA the concept of Developmental- Behavioural pediatrics was first accredited by AAP as sub-specialty in the year $1999 .{ }^{14}$ It will definitely take lot of time for us to grow but without good beginning it's not possible. This study will provide direction for the ongoing refinement of pediatric education that is based on feedback from currently practicing pediatricians.

\section{CONCLUSION}

Pediatricians working in Nepal have difficulties in addressing the issues of developmental pediatrics, due to inadequate training on DBP issues during the post graduate training in pediatrics in developing country. Therefore there is a need to review the curriculum of post graduate training in Pediatrics. Being a study based on a survey there may be a question of external validity, hence generalization of the results.

\section{ACKNOWLEDGEMENT}

Our sincere gratitude to the school authority and the participating students without their support this study wouldn't have been possible. We are thankful to $\mathrm{Mr}$ Dharanidhar Baral for his support on statistical analysis.

\section{REFERENCES}

1. Blanchard LT, Gurka MJ, Blackman JA. Emotional, developmental, and behavioral health of American children and their families: a report from the 2003 National Survey of Children's Health. Pediatrics. 2006;117(6):1202-12.

2. Haggerty RJ RK, Pless IB, eds. Child Health and the Community. New York, NY: John Wiley and Sons. Haggerty RJ, Roghmann KJ, Pless IB, eds. Child Health and the Community. New York, NY: John Wiley and Sons; 1975.

3. Nielsen BA, Baum RA, Soares NS. Navigating ethical issues with electronic health records in developmental-behavioral pediatric practice. Journal of developmental and behavioral pediatrics : JDBP. 2013;34(1):45-51.

4. Schor EL, Elfenbein C. A need for faculty development in developmental and behavioral pediatrics. Issue brief (Commonwealth Fund). 2004(785):1-8.

5. Grant E, Macnab A, Wambera K. The effectiveness of pediatric residency education in preparing graduates to manage neurological and neurobehavioral issues in practice. Academic medicine : journal of the Association of American Medical Colleges. 2007;82(3):304-9.

6. Chee KY, Simpson JM, Hutchins P. Survey on developmentalbehavioural training experiences of Australian paediatric advanced trainees. Journal of pediatrics and child health. 1994;30(6):478-82.

7. Boreman CD TM, Fernandez SA, Coury DL, 2007; CPP. Resident training in developmental/behavioral pediatrics: where do we stand? Clinical pediatrics. 2007;46:46:135-145.:46:135-45.

8. Atilola O, Singh Balhara YP, Stevanovic D, Avicenna M, Kandemir H. Selfreported mental health problems among adolescents in developing countries: results from an international pilot sample. Journal of developmental and behavioral pediatrics : JDBP. 2013;34(2):129-37. 
9. Wu LA, Katz J, Mullany LC, Khatry SK, Darmstadt GL, LeClerq SC, et al. The association of preterm birth and small birthweight for gestational age on childhood disability screening using the Ten Questions Plus tool in rural Sarlahi district, southern Nepal. Child: care, health and development. 2012;38(3):332-40.

10. Suvarna BS, Kamath A. Prevalence of attention deficit disorder among preschool age children. Nepal Medical College journal NMCJ. 2009;11(1):1-4.

11. Bravender T. School performance: the pediatrician's role. Clinical pediatrics. 2008;47(6):535-45.
12. Holt JM, McDowell MJ. Developmental-behavioural problems in general pediatrics. Journal of pediatrics and child health. 1998;34(3):245-9.

13. Jan MM. Pediatric neuro-developmental and behavioral disorders. Practitioners' perspectives. Neurosciences (Riyadh, Saudi Arabia). 2005;10(2):149-54.

14. Stockman JA, 3rd. Developmental-behavioral pediatrics: the American Board of Pediatrics' perspective. Journal of developmental and behavioral pediatrics : JDBP. 2000;21(2):133-5. 